\title{
THE DIFFICULTIES ENCOUNTERED BY WOMEN IN PURSUING A MANAGERIAL CAREER IN SPORTS
}

\author{
Sonia ALBU ${ }^{1 *}$, Vasilica GRIGORE ${ }^{1}$ \\ ${ }^{1}$ National University of Physical Education and Sport, Faculty of Physical Education and Sport, \\ Bucharest, Romania \\ *Corresponding author: albu.sonia@yahoo.com
}

https://doi.org/10.35189/dpeskj.2020.59.s.6

\begin{abstract}
With considerable efforts, women have made remarkable progress and have become increasingly present in the sporting phenomenon, both as athletes and in various management positions. However, compared to men, they are still under-represented in the management positions of sports organizations, especially at senior management levels. According to the European Institute for Gender Equality (European Commission, 2014), the percentage of women in management positions in leading sports organizations was very low in 2014 (an average of 10\%); also, out of 52 European sports federations, 20 had no women on their federal boards and only two had women as presidents. In 2017, out of the 74 national sports federations in our country, only 7 had female presidents. We should also not forget that there are still situations where women are paid less than men for work of equal value (according to the same European Institute for Gender Equality, women would earn 2 euros per hour less than men, on average). Given these data, we wanted to identify the difficulties encountered by women in managerial careers. For our study, we conducted a series of interviews with women managers in sport organizations from our country. The interviews had pre-determined questions and were focused on issues such as: gender discrimination, differences in remuneration between women and men, barriers and obstacles to promoting at work, difficulties and limitations encountered by women in pursuing their managerial careers.
\end{abstract}

Keywords: gender equality, women managers, sports management.

\section{Introduction}

The issue of gender equality and the eradication of any form of discrimination is a global concern for the international organizations in terms of developing policies regarding work, education and various social issues. Intense concerns are also found at national level for the implementation of decisions and recommendations regarding the issues mentioned above. Although mankind has made great strides towards eradicating the issues addressed through this paper, women involved in the sports field (as athletes or employed in organizations) are part of organizations in which, even today, it is observed that there is a certain level of discrimination based on different criteria, such as gender.

Article 21 of the Charter of Fundamental Rights of the European Union states that discrimination of any kind, based on grounds such as sex, is prohibited (European Union, 2012). Also, since the publication of the Universal Declaration of Human Rights (1948), Romania has developed and adopted a series of national policies in the field of human rights in order to harmonise with European requirements. Romania is now a signatory to the 2030 Agenda, which aims to prevent and reduce discrimination and ensure equal opportunities. The 2030 agenda has several objectives, but for this paper, we mention number 5 and number 10 in the document, those aimed at gender equality and reduced inequalities, because it correlates with our interest throughout this study. 
Curșeu and Boroș (2008) consider that the woman's path to superior management positions is presented in the literature as being paved with glass or, more precisely, with "shards of glass". The most common concept is the "glass ceiling", which means the possibility for women to advance in management positions only up to a certain point. Statistics from recent decades have identified an upward curve in the presence of women in leadership positions, but only for the middle level of organizations (middle management), while for top management positions women still have a very small percentage of representation. Hejase and Nohra (2017) also state that the female workforce is considered a competitive advantage to most of the economic sectors with high representation in lowerranked jobs but not in higher-ranked jobs.

Given the above, we wanted to see the concrete situation of gender equality in sports because, in pursuing a managerial career, women often encounter various obstacles and limitations. This is all the more true in a field like sport, which has been dominated by men throughout history. According to the European Institute for Gender Equality (European Commission, 2014), there were only three female presidents among national Olympic committees from the European Union countries, and the percentage of women on the executive boards of national Olympic committees was 14\%; also, the employment rate was lower for women than men. It is also worth mentioning that the position of president of the International Olympic Committee has been held only by men since its establishment (1894) until now, and the Romanian Olympic and Sports Committee has so far had only one female president, Lia Manoliu.

Studies conducted in Romania in recent years have highlighted the high share of gender stereotypes in terms of leadership and management activities. In a study regarding gender equality conducted at national level, Gender Barometer - Romania 2018 (Grünberg, 2018), more than $70 \%$ of the 1140 respondents considered that cooking, house cleaning, washing clothes, doing the dishes, ironing, etc. are activities performed only by women, $44 \%$ said that women are too busy with household chores and no longer have time for management positions, $61 \%$ of the respondents considered that it is the duty of men rather than women to bring money into the house, and 70 said the man is the "head of the family". This shows that Romania is still a country with traditional values where women have to take care of household chores and men have to work.

The Romanian National Agency for Equal Opportunities between Women and Men (Agenția Națională pentru Egalitate de Șanse între Femei și Bărbaţi, 2018) developed a national strategy for 2018-2021 aimed to promote equal opportunities and treatment for women and men and prevent domestic violence, in which some important data can be found for 2016:

- In Romania, the employment rate (for the age group 20-64 years) was 75.0\% for men and $57.4 \%$ for women; in the European Union, it was $65 \%$ for women and $77 \%$ for men;

- Men were majority in the following categories: qualified workers: $79.0 \%$ compared to only $21.0 \%$ women; senior leaders in public administration: $66.4 \%$ compared to only $33.6 \%$ women; qualified workers in agriculture, forestry and fisheries: $55.2 \%$ compared to $44.8 \%$ women; 
- Women predominated in the following positions: administrative officials without management positions $61.8 \%$; customer service workers $61.5 \%$; specialists in various fields of activity $56.1 \%$.

As presented above, women are still represented in a small percentage in management positions, and this is also due to gender discrimination. Curșeu and Boroș (2008) organized a hypothetical task of staff selection to highlight the extent to which women were disadvantaged and discriminated when applying for management positions. A total of 213 men were asked to choose between two candidates for manager based on their curriculum vitae. In the control group, they had to choose between two men, and the percentages for the two CVs were $40 \%$ and $60 \%$, respectively. Then, for the experimental group, in the CV preferred by the control group (chosen by $60 \%$ of the study participants), the gender was changed, specifying that the candidate was a woman. The consequence of this change was that, when the gender of the applicant changed, the CV preferred by the control group became less chosen by those from the experimental group (chosen by $40 \%$ of the study participants). To expand the study and explore the extent to which these gender stereotypes affected female respondents, 147 women were asked to perform the same task. Surprisingly, in the case of women, there was a radical change (even more pronounced than in the case of men) of preferences after the change of gender in one of the CVs, respectively: $58 \%-42 \%$ in the control group turned into $27 \%-73 \%$ in the experimental group. These data have demonstrated once again the strong impact that gender stereotypes have in Romania, in the selection for management positions.

Regarding career barriers for women in sport management, women often think that they have to work harder to get promoted and that they receive negative reactions and feedback due to being women (Kara et al., 2016). Hindman and Walker (2020) postulate that women remain the minority in sport organizations, especially in leadership roles, and previous work has suggested that sexism may be to blame; according to their findings, the culture of sports organizations perpetuates sexism, including the objectification and diminishment of women. The above authors believe that sexism occurs in women's daily interactions with their supervisors and co-workers, but also others with whom they interact as part of their jobs, and such experiences result in professional and emotional consequences. On the other hand, Simmons (2011) concludes that "the 'glass ceiling' may not be as high as we once thought" (p. 20) and believes that women who have the desire to work in the Sport Industry have a promising future. However, the engagement of women in sport management demands certain sacrifices and challenges that are balanced out mostly by the support received from their family members (Daud et al., 2013). Thompson (2017) reaches a surprising finding regarding women managers: whereas senior women may have been expected to be just as or even more beleaguered than their middle-ranking colleagues, those who hold high-ranking positions are thriving in their roles.

Werhane (2019) states that women in executive or managerial positions are more likely to be flexible, usually tend to be collaborative rather than directive and are better at understanding the complex relationships that particularly develop in a global economy. The above author also believes that women are less fearful to hire their successors and, as transformational leaders, are often better than their male counterparts in systems thinking. 
Also, several authors have studied the hierarchical relationships between women in the workplace: do women managers support other women? The study by Abalkhail (2020) shows that, despite senior women having supported other women's career advancement, this support tended to be conditional and limited. Other research by Leberman (2017) shows that women expect a higher degree of emotional understanding and support from a woman manager than from a man and they also expect a woman manager to see them as an equal. Hurst et al. (2016) think that the influence of hierarchical relationships between women in the workplace on their career development is under-researched.

Last but not least, a problem still encountered by women, which should not be ignored, is sexual harassment at work. The research by Echiejile (1993) showed that the incidence of sexual harassment at work had risen dramatically and this was a cause for concern. Quick (1998) believed that sexual harassment at work was a continuing, chronic occupational health psychology problem. The results of a survey by Ford and McLaughlin (1988) showed that, although sexual harassment caused problems in companies, human resource managers did not even agree on the action to be taken for different levels of harassment. According to Folke et al. (2020), "sexual harassment is more prevalent for women supervisors than for women employees" (p. 180). Their research findings show that, among supervisors, the risk is higher in lower- and mid-level positions of leadership as well as when subordinates are mostly male. They conclude that "sexual harassment is a workplace hazard that raises the costs for women to pursue leadership ambitions and, in turn, reinforces gender gaps in income, status and voice" (Folke et al., 2020, p. 180).

The sports field has been dominated by men for a long time in history. We can think of the Ancient Olympic Games, where women were not allowed to participate. It is also worth mentioning that, even at the first edition of the Modern Olympic Games, in 1896, women were not allowed to participate. Not until the 2012 Olympic Games did all the participating delegations include women, their inclusion in the world of sports, as athletes or managers, being achieved gradually.

\section{Research purpose}

The aim of this study was to identify the obstacles felt by women managers in the sports field during their careers.

\section{Methodology}

The research methods used for this study were: literature review and interview survey to collect the necessary data, mathematical and statistical method to process the obtained data and graphical representation to suggestively illustrate the results (Figure 1).

\section{Literature review}

Interview survey

Figure 1. Research methods used 
The conducted interview was structured and had 6 pre-determined questions intended to highlight the existence or not of any form of discrimination, limitation or barrier in the respondents' professional lives. The participants, 13 women managers in sports organizations, freely expressed their consent to answer our questions.

\section{Results}

The present study about the difficulties encountered by women in pursuing a managerial career in sports is part of a larger research regarding gender equality in sports management. This study on gender equality was conducted over a period of 3 years and we hope that, through the results presented in this paper, we can bring more information on this topic. We have chosen the field of sport because it represents a widespread and popular human activity; it is particularly rich in offers and has a great impact on the quality of life of those who practice it. Nowadays, many women work in sports and, regardless of their level in an organization, they contribute to the success of the organization and help maintain it in the top.

Given that the sports field has historically been dominated by men, we wanted to identify the main obstacles, difficulties and limitations felt by women managers. For this, we conducted a series of interviews with 13 women managers from national sports organizations. Of the 13 women managers, 5 are in management positions in national sports federations (president, vice-president or general secretary) and 8 are presidents of national sports clubs. Also, most of the managers interviewed are former athletes, so they have been involved in the sports field much of their lives, their opinion being one of real value. We want to emphasise once again that, although some women have started to obtain top management positions and we were able to find these 13 sports women managers for our interview, this does not mean that women do not continue to face gender discrimination and encounter difficulties and obstacles in their careers because of their gender.

The interviews had 6 pre-determined questions and were focused on issues such as: gender discrimination, differences in remuneration between women and men, barriers and obstacles to promoting at work, difficulties and limitations encountered by women in pursuing their managerial careers.

First of all, we wanted to find out if the women managers participating in our study ever felt discriminated against because of their gender. $46.15 \%$ of the women interviewed felt discriminated during their career in sports, while $53.85 \%$ did not encounter this situation (Figure 2).

Our second question was about equal pay issues. Only $7.69 \%$ of the 13 women interviewed encountered this kind of issues in their careers (Figure 3). It should be mentioned that, according to the Report on Equality between Women and Men in the EU (European Commission, 2018), Romania is the EU Member State where the pay gap has the lowest level, 5.2\%. Borge Brende, President of the World Economic Forum, stated that the only important step a country, company or organization can take if it wants to maximise its potential is to achieve gender equality. 


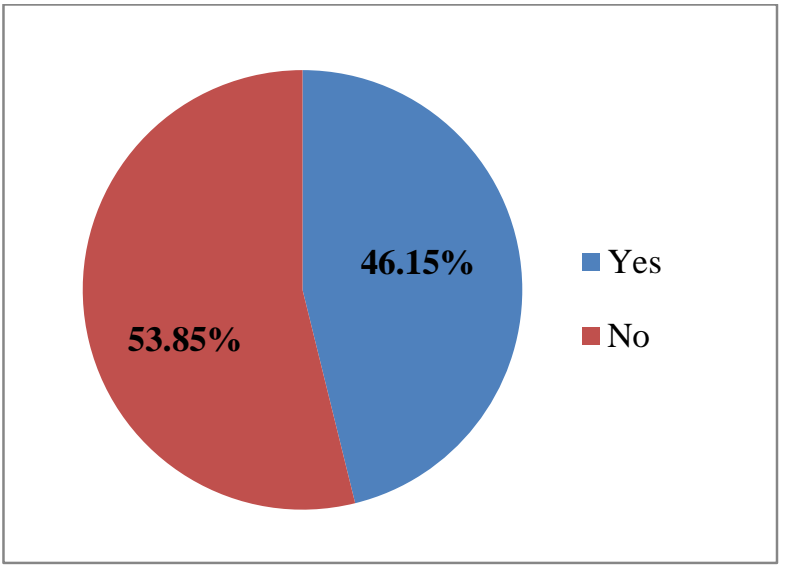

Figure 2. In your career, have you ever felt discriminated against because of your gender?

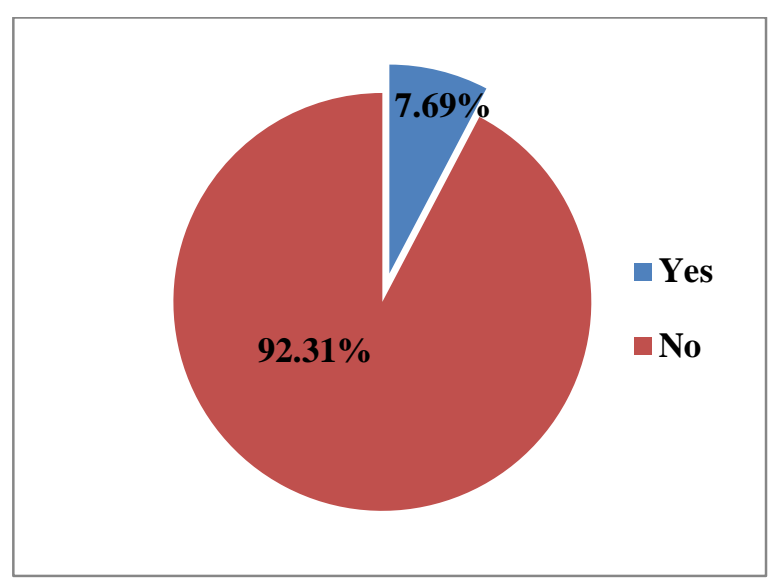

Figure 3. Have you ever encountered equal pay issues between the two genders?

The practical application of pay equality still remains a real problem, even though the majority of EU Member States have adopted the necessary legislative framework to ensure gender equality. In Romania, remuneration differences between men and women are much lower in comparison with other states, but the effects are fully felt due to the low level of salaries present in the internal labour market. (Florişteanu \& Florişteanu, 2015)

To the third question of our interview ("Have you had the same benefits as men in your career?"), $61.54 \%$ responded "yes", while $38.46 \%$ said they did not have the same benefits as men in their careers (Figure 4). Regarding the fourth question, 23.08\% of the managers interviewed consider that there are barriers and/or obstacles that have prevented them from being promoted at work as quickly as men (Figure 5).
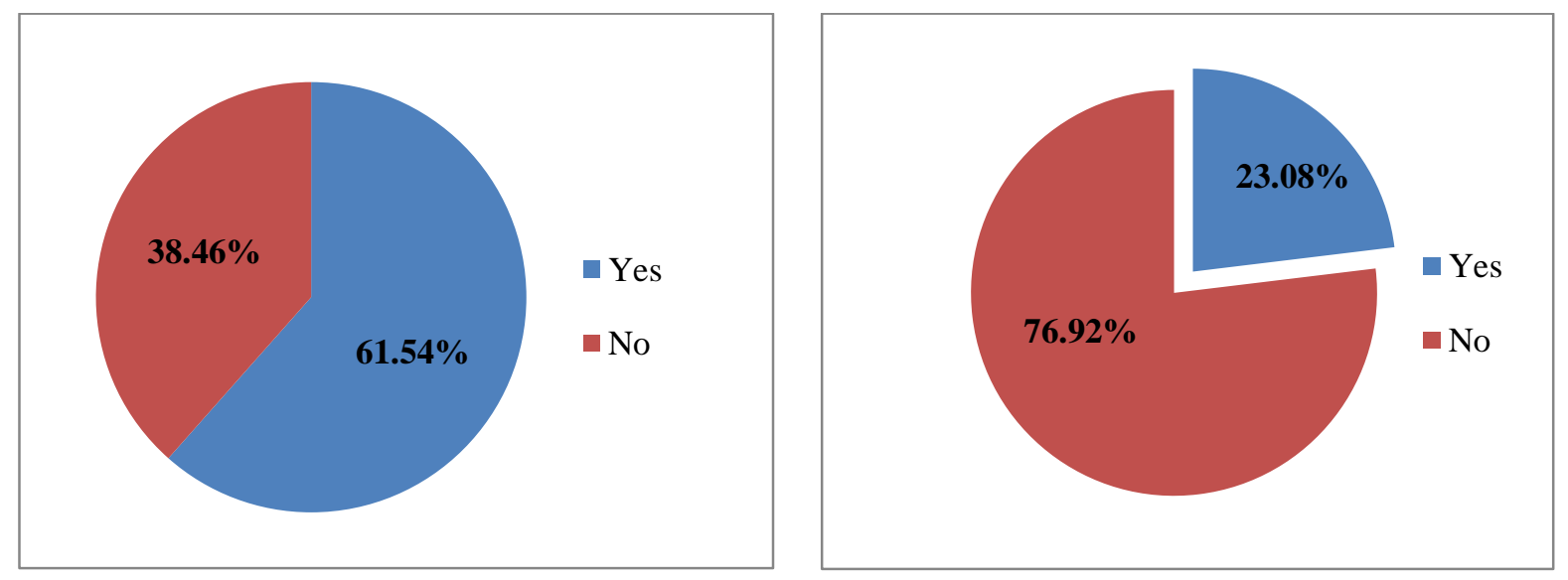

Figure 4. Have you had the same benefits as men in your career?

Figure 5. Do you consider that there are barriers and/or obstacles that have prevented you from being promoted at work as quickly as men?

Bosak (2015) believes that one of the main causes for women's power deficit is the "glass ceiling" phenomenon, specifically the societal stereotypes that result in discrimination and prejudice for women. Blackmore (1999) emphasises that authority has been associated over 
time "with hegemonic masculinity and women who manage are insiders with institutional power and authority but who stand outside the male culture" (p. 107).

Furthermore, we asked our managers what they considered to be the main obstacles, difficulties and limitations encountered by women in their professional careers (regarding promotion to a managerial position). Below, we present a summary of their opinions:

- finding a balance between family and professional life;

- preconceived ideas about women in management positions;

- gender discrimination against women;

- the traditional social roles of women and men in our society;

- sports environment and culture are predominantly masculine;

- under-estimating the ability of women to adapt to the demands imposed in the field of sports and to assert themselves in front of employees.

"Finding a balance between family and professional life" and "preconceived ideas" were the most encountered difficulties by the women we interviewed. It seems that efforts are needed in order to achieve a more flexible work schedule that would allow women to find a balance between family and professional life. Also, several managers have stated that there are still many preconceived ideas regarding women in management positions, especially in the sports field. Traditional roles should not be ignored either, given that Romania is still a country with strong traditional values. Last but not least, one of the women interviewed had an interesting observation: she considers that the environment and culture in the sports field are predominantly masculine, and this makes it more difficult for women to promote in their careers.

Lastly, we asked the participants in our interviews if they had an opinion, idea or solution that they could/would like to share with us on solving the problems identified by them. Next, we summarise their answers:

- flexibility of the work schedule to allow a balance between family and professional life;

- imposing gender quotas within each organization;

- gender parity in organizations;

- promoting gender equality in all sports organizations;

- men are still paid better than women especially as athletes, not necessarily as managers;

- elderly men are more reluctant than young men regarding women managers;

- some women do not have enough confidence in themselves and their own skills and abilities;

- women have a higher chance to hold management positions in predominantly "female sports" (like rhythmic gymnastics).

Most of the managers interviewed consider that flexibility of the work schedule to allow a balance between family and professional life, imposing gender quotas within sports organizations and promoting gender equality are some of the measures that can be implemented to reduce gender discrimination and facilitate women's access to management positions. Also, one of the women interviewed drew attention to the salary differences between athletes, men being paid much better than women. Perhaps these gender pay gaps that we encounter in sports should be adjusted and addressed from the very beginning, starting with athletes and then with those in various management positions. Another manager 
interviewed stated that the main obstacle encountered was in her relationship with older men in sports. She considers that young people are much more open about women managers in this field.

Adriaanse and Schofield (2014) state that a common practice to address women's underrepresentation in governance has been the introduction of gender quotas. Their findings suggested that a quota of a minimum of three women was a first condition to advance gender equality in governance.

According to the guide Gender Equality in Sport - Proposal for Strategic Actions 20142020 (European Commission, 2014), the fight against gender stereotypes in sport and equal representation in the decision-making of the two genders should be priorities for all EU states. The European Institute for Gender Equality also considers that all sports organizations and governing bodies should have a gender equality policy, including an action plan, and that women should be represented in a percentage of at least $40 \%$ in the executive boards and in the commissions of the national sports federations, as well as in the management of the governmental sports organizations. We believe that the sports organizations from our country can implement more measures to comply with the European recommendations and get closer to that target of "gender balance".

Our findings show that, in the sports field in our country, there are still certain difficulties and limitations felt by women in their careers. We have also identified some of these obstacles and difficulties, meaning that our study has reached its goal.

\section{Conclusion}

Women are still under-represented in management positions in sports organizations, a field dominated by men, and the reasons for this situation are complex. They face many difficulties during their careers and often feel discriminated. Regarding the limitations of our study, although our sample was small and we cannot generalise the conclusions obtained, we believe that through our research we can bring more information about the issue addressed. Taking into account the given answers, $46.15 \%$ of the women interviewed by us felt discriminated and $38.46 \%$ considered they didn't have the same benefits as men. Also, $23.08 \%$ of managers interviewed considered that there are barriers or obstacles that have prevented them from being promoted at work as quickly as men. On a positive note, only $7.69 \%$ of the 13 women interviewed encountered equal pay issues in their career, our country being one where the pay gap has a low level.

According to our results, some of the main obstacles and difficulties encountered by women in their professional careers are: finding a balance between family and professional life, preconceived ideas regarding women in management positions, gender discrimination against women, the traditional social roles of women and men in our society, sports environment and culture being predominantly masculine, underestimating the abilities of women. The managers we interviewed also offered us some ideas that could facilitate women's access to the hierarchy of sports organizations: flexibility of the programme to allow a balance between family and professional life, imposing gender quotas within sports organizations, promoting gender equality in all sports organizations. 
We believe that gender equality should be a goal of any sports organization. The approach of this issue should be made in the field of sports, both for practitioners and among management positions. More attention should be paid to possible future measures in terms of creating real opportunities for women so as to reach a higher level of equality. Increasing the level of information among the population regarding gender discrimination, eradicating prejudices, correct appreciation of women's abilities could also help increase women's confidence in their own ability and motivation to try to build a career in sports. We are aware that these types of measures take time, but we believe that both in our country and in Europe there is an interest in achieving gender equality and more measures have started to be implemented in this direction.

Although remarkable progress has been made and women become increasingly present in various management positions, there are still many situations in which women are discriminated and this has to change. Given the data presented above, we consider that addressing the issue of difficulties encountered by women in pursuing a managerial career in sports in our country is of real importance. It is necessary to comply with the requirements and recommendations of the European Union if we want to improve the representation of women in management positions, as well as the status of women managers in sports.

\section{Acknowledgement}

This paper is part of a research conducted during doctoral studies at the National University of Physical Education and Sport, Bucharest.

\section{Authors' Contributions}

Both authors have equally contributed to this study and should be considered as main authors.

\section{References}

Abalkhail, J. M. (2020). Women managing women: Hierarchical relationships and career impact. Career Development International, 25(4), 389-413. https://doi.org/10.1108/CDI-01-2019-0020

Adriaanse, J., \& Schofield, T. (2014). The impact of gender quotas on gender equality in sport governance. Journal of Sport Management, 28(5), 485-497. https://doi.org/10.1123/jsm.2013-0108

Agenția Naţională pentru Egalitate de Șanse între Femei și Bărbați. (2018). Strategia națională privind promovarea egalității de șanse și de tratament între femei și bărbați și prevenirea și combaterea violenței domestice pentru perioada 2018-2021 [National strategy on promoting equal opportunities and treatment for women and men and preventing domestic violence for 2018-2021]. https://anes.gov.ro/wp-content/uploads/2018/06/Strategia-Nationala-ES-si-VD.pdf

Blackmore, J. (1999). Troubling women. Feminism, leadership and educational change. Buckingham: Open University Press.

Bosak, J. (2015). Women managers. In Wiley Encyclopedia of Management (Vol. 11: Organizational behavior). https://doi.org/10.1002/9781118785317.weom110085 
Curșeu, P. L., \& Boroș, S. (2008). Stereotypes and prejudice towards women managers: An experimental illustration using the Goldberg paradigm in a Romanian sample. Studia Psychologica, 50(3), 233-254.

https://www.researchgate.net/publication/254836541_Stereotypes_and_prejudice_towards _women_managers_An_experimental_illustration_using_the_Goldberg_paradigm_in_a_R omanian_sample

Daud, M. A. K. M., Radzi, W. M., Abdullah, R., \& Johari, F. (2013). The participation of women managers in managing sport: Challenges and reality. Life Science Journal, 10(3), 870-878. http://www.dx.doi.org/10.7537/marslsj100313.130

Echiejile, I. (1993). Dealing with sexual harassment at work. Employee Counselling Today, 5(4), 21-29. https://doi.org/10.1108/13665629310044730

European Union. (2012). Charter of Fundamental Rights of the European Union. https://eurlex.europa.eu/legal-content/EN/TXT/PDF/?uri=CELEX:12012P/TXT\&from=EN

European Commission. (2014). Gender equality in sport: Proposal for strategic actions 2014-2020.

https://ec.europa.eu/assets/eac/sport/events/2013/documents/20131203-gender/finalproposal-1802_en.pdf

European Commission. (2018). 2018 Report on equality between women and men in the EU. file://C:/Users/40726/Downloads/2018ReportonequalitybetweenwomenandmenintheEU\% 20(1).pdf

Florişteanu, E., \& Florişteanu, I. D. (2015). Equal pay as an objective of gender equality. International Conference "Knowledge-Based Organization", 21(2), 300-307. https://doi.org/10.1515/kbo-2015-0051

Folke, O., Rickne, J., Tanaka, S., \& Tateishi, Y. (2020). Sexual harassment of women leaders. Daedalus, 149(1), 180-197. https://doi.org/10.1162/daed_a_01781

Ford, R. C., \& McLaughlin, F. S. (1988). Sexual harassment at work. Business Horizons, 31(6), 14-19. https://doi.org/10.1016/0007-6813(88)90018-3

Grünberg, L. (Coord.) (2019). Barometru de Gen - România 2018 [Gender Barometer Romania 2018]. https://centrulfilia.ro/new/wp-content/uploads/2019/08/Barometru-degen-2018.-Centrul-FILIA.pdf

Hejase, H. J., \& Nohra, P. (2017). Women in management. Al Maaref University Lecture Series. DOI: 10.13140/RG.2.2.16128.94726

Hindman, L. C., \& Walker, N. A. (2020). Sexism in professional sports: How women managers experience and survive sport organizational culture. Journal of Sport Management, 34(1), 64-76. https://doi.org/10.1123/jsm.2018-0331

Hurst, J., Leberman, S., \& Edwards, M. (2016). Women managing women: Intersections between hierarchical relationships, career development and gender equity. Gender in Management, 31(1), 61-74. https://doi.org/10.1108/GM-03-2015-0018

Kara, F. M., Çolakoğlu, T., \& Erturan Ogut, E. E. (2016). Career barriers of women managers in sports organisations. International Journal of Sports Exercise and Training Science, 2(3), 82-92. https://doi.org/10.18826/ijsets.04634

Leberman, S. (2017). The relational expectations of women managing women. Gender in Management, 32(1), 19-33. DOI: 10.1108/GM-02-2016-0016

Quick, J. C. (1998). Sexual harassment at work. Introduction. Journal of Occupational Health Psychology, 3(1), 3-6. https://psycnet.apa.org/doi/10.1037/h0092743

Simmons, K. (2011). Women in top management positions in the sport industry: Breaking down the barriers and stereotypes (Sport Management Undergraduate, Paper 22). St. John Fisher College: Fisher Digital Publications. https://core.ac.uk/download/pdf/48617106.pdf 
Thompson, B. (2017). Extraordinary women: Senior women managers and leaders. In Gender, management and leadership in initial teacher education (pp. 189-217). London: Palgrave Macmillan. https://doi.org/10.1057/978-1-137-49051-3_8

Werhane, P. H. (2019). Women leaders in a globalized world. In D. Bevan, R Wolfe, \& P. Werhane (Eds.), Systems thinking and moral imagination (Vol. 48: Issues in Business Ethics, pp. 229-244). Springer, Cham.

http://doi-org-443.webvpn.fjmu.edu.cn/10.1007/978-3-319-89797-4_13 